\title{
Significados e limites das estratégias de integração disciplinar: uma reflexão sobre as contribuições da saúde do trabalhador
}

\author{
M eanings and limits concerned to the strategies \\ of disciplinary integration: a reflection about \\ the contributions from the workers' health field
}

M arcelo Firpo de S. Porto 1

Gláucia E. S. de Almeida 2

1 Centro de Estudos de Saúde do Trabalhador e Ecologia Humana, Escola Nacional de Saúde Pública, Fundação Oswaldo Cruz. Rua Leopoldo Bulhões 1480, Manguinhos, 21041-210,

Rio de Janeiro RJ.

firpo@ensp.fiiocruz.br

2 Instituto de Medicina

Social da Universidade

Estadual do Rio de Janeiro.

\begin{abstract}
Although the terms multidisciplinarity, interdisciplinarity and transdisciplinarity are often used in the literature of the public health field, and more specifically in the worker's health and environmental health fields, there is a relative lack of texts which deepen their theoretical-conceptual discussion and methodological implications. This article has a theoretical and exploratory character and intends to give some conceptual support to discuss the importance of integrating disciplines, pointing out some challenges and perspectives for the implementation of academic works with these characteristics. The article is based on a critical revision of some authors, on our personal paths in multiprofissional research groups, on the reflection about the evolution and the characteristics of the worker's health area, as well as on a study with researchers of different Brazilian research institutions of Public Health who work with workers' and environmental health issues. The results of this study generated a master's degree dissertation (Almeida, 2000).
\end{abstract}

Key words Interdisciplinarity, Transdisciplinarity, Public health, Workers' health, Environmental health
Resumo Embora os termos multidisciplinaridade, interdisciplinaridade e transdisciplinaridade sejam recorrentes na literatura do campo da saúde coletiva, e mais especificamentena saúde do trabalhador e saúde ambiental, existe uma relativa carência de textos que aprofundem sua discussão teórico-conceitual eimplicações metodológicas. Este artigo, de caráter teórico e exploratório, se propõe a fornecer alguns balizamentos conceituais e a discutir a importância das estratégias de integração disci plinar, apontando al guns desafios e perspectivas para a implementação de trabal hos com estas características. 0 artigo se apóia na revisão crítica de al guns autores, em nossas trajetórias pessoais em grupos multi profissionais de pesquisa, na reflexão sobre a evolução e as características da área de saúde do trabalhador no país, assim como em estudo realizado junto a pesqui sadores de diferentes insti tuições brasileiras de pesquisa em saúde col etiva relacionadas à temática saúde, trabalho e ambiente, cujos resultados geraram uma dissertação de mestrado (Almeida, 2000).

Palavras-chave Interdisciplinaridade, Transdisciplinaridade, Saúde coletiva, Saúde do trabalhador, Saúde ambiental 


\section{Introdução}

As noções de multidisciplinaridade, interdisciplinaridade ou transdisciplinaridade são freqüentemente utilizadas por autores que buscam definir o campo da saúde do trabalhador (Tambellini et al., 1986; M inayo-Gomez eThe dim-Costa, 1997; M endes e Dias, 1991; Lacaz, 1997), como se a compreensão dos mesmos fosse assunto esgotado ou de senso comum. Entretanto, praticamente inexistem definições conceituais ou propostas metodológicas mais claras acerca desses termos nesta área, tendo sido levantado apenas um artigo específico de autor nacional (Tambellini, 1994), ainda que em publicação estrangeira. A discussão em torno de tais conceitos na saúde coletiva é ainda relativamente recente (M inayo, 1994; Almeida Filho, 1997; Tarride, 1998; Paim eAlmeida Filho, 2000; Samaja, 2000), sendo mais antiga e sistemática a produção de textos no campo da filosofia, das ciências sociais e humanas, e das ciências ambientais.

Face à carência de referências que aprofundem a discussão teórico-conceitual desses termos na produção de conhecimento em saúde, trabal ho e ambiente, este trabalho, de caráter teórico-conceitual e exploratório, se propõe a fornecer alguns balizamentos conceituais e discutir a importância das estratégias de integração disciplinar, apontando alguns desafios e perspectivas para a implementação de trabalhos com estas características.

Este artigo é apoiado na revisão crítica de vários autores; em entrevistas e questionários respondidos por alguns pesquisadores de diferentes instituições brasileiras de pesquisa em saúde pública, relacionadas à temática saúde, trabalho e ambiente, cujos resultados geraram uma dissertação de mestrado (Almeida, 2000); eem nossas trajetórias pessoais em grupos multiprofissionais de pesquisa envolven do a relação saúde, trabalho e ambiente.

Nos primeiros itens do artigo, levantamos a origem dos debates na crítica aos limites da disciplinaridade restrita e da ciência normal na produção do conhecimento; organizamos os autores referenciados a partir de três vertentes principais (a humanista, a social crítica e a da complexidade); e discutimos os significados dos termos multidisciplinaridade, interdisciplinaridade e transdisciplinaridade como as três principais estratégias de integração disciplinar utilizadas. Na parte final do trabalho, aprofundamos as contribuições para o desenvolvimen- to de estratégias de integração disciplinar provenientes da área de saúde do trabal hador ou, em uma perspectiva mais abrangente, do estudo das relações em saúde, trabal ho e ambiente.

\section{0 nascimento da ciência moderna pela disciplinaridade restrita ou ciência normal}

0 desenvolvimento de estratégias de integração disciplinar na produção de conhecimento surge como resposta às críticas decorrentes do modelo de conhecimento científico que, a partir do século 16 , se impôs para o pensamento ocidental como o principal recurso para a transformação dos processos de produção e das condições de vida, constituindo o que passou a ser identificado como "ciência moderna". Assim, 0 milagre da ciência natural moderna reside na possibilidade de estender a experiência de laboratório - o estudo do fragmento que foi isolado da natureza e conservado artificial mente puro, estável e reprodutível - à compreensão e ao controle da natureza em estado bruto. Juntas, a tecnologia e a medicina tornaram-na previsível e, em parte, controlável, permitindo que muita gente desfrutasse de uma vida mais segura e confortável que a vigente em qualquer outra época da história (Funtowicz \& Ravetz, 1997).

Uma característica central do método científico cartesiano é a fragmentação da realidade estudada: o conhecimento racional implica a decomposição da coisa a ser conhecida por meio de uma série de operações que reduziam-na às suas partes mais simples (Almeida Filho, 1997). A monodisciplinaridade ou disciplinaridade restrita pode ser entendida como uma estratégia de organização histórico-institucional da ciência baseada na fragmentação do objeto e na especialização do sujeito científico, o pesquisador, cujo sucesso se realiza através de teorias e experimentos validados pela comunidade de pares científicos. Esta estratégia manteve os pesquisadores rigorosamente em suas áreas específicas de atuação, ascéticos e perseverantes no enfrentamento dos problemas particulares da seara para a qual foram formados (Almeida, 2000).

Um dos resultados desse processo foi o forjar da divisão entre as várias áreas de conhecimento e disciplinas correlatas, como a física, a biologia, as ciências sociais e humanas, bem como suas aplicações em áreas como as ciências médicas, as engenharias, a economia e a admi- 
nistração. Rebatido no estudo das relações em saúde, trabalho eambiente, tal processo de divisão do conhecimento gerou disciplinas e métodos específicos de análise e solução de problemas em função dos corpos (ciências biomédicas) e mentes afetadas ( psicologia), do ambiente interno à fábrica (engenharias, administração e demais disciplinas envolvidas no projeto e gestão dos processos produtivos), e do ambiente externo, incluindo a esfera biológica, espacial e social (ecologia, geografia, sociologia, antropologia, economia) (Porto e Freitas, 1997).

A dinâmica que permitiu a evolução e o relativo sucesso dessa forma de fazer ciência foi descrita por Thomas Kuhn em seus trabalhos no campo da história efilosofia das ciências nos idos dos anos 60 (Kuhn, 1987), e que se cel ebrizaram através da difusão dos conceitos de paradigma e ciência normal, este correlato ao de disciplinaridade restrita. Para Kuhn, as disciplinas científicas são conformadas historicamente por um dado paradigma, que compreende o conjunto de regras, princípios e instrumentos que permitem entender e classificar determinados fenômenos dentro de uma certa visão de mundo. Os paradigmas evoluem por meio de revoIuções científicas, em consonância com novas demandas históricas e novos referenciais teóricos, onde os fenômenos são redefinidos através de novos paradigmas que substituem os anteriores.

Tal proposição, acompanhada posteriormente da evolução da sociologia do conhecimento científico (Collins, 1983; Latour, 1994), constituiu-se num profundo golpe à suposta objetividade científica, ao revelar como os objetos científicos existem somente em relação, e que a ciência é a materialização de projetos sociais e políticos, sendo, portanto, uma construção humana, histórica e em permanente transformação (Almeida, 2000). Como discutem M aturana e Varela (1991), numa abordagem científica contemporânea o cientista compreende que seu objeto é, necessariamente, também a visão que ele próprio possui sobre o problema. Recentes contribuições decorrentes da noção de complexidade e da compreensão de que a separação entre sujei to e objeto coloca um profundo obstáculo para a construção de uma prática científica ética e democrática, sugerem como alternativa à estrutura ainda hegemônica da ciência normal a construção de uma ciência pós-normal, de caráter reflexivo e integrador entre diferentes dimensões e saberes (Funtowicz e Ravetz, 1994 e 1997).

\section{As críticas à disciplinaridade restrita e suas vertentes}

A crítica aos limites da disciplinaridade restrita e da ciência normal, às suas características e suas conseqüências para a sociedade e o meio ambiente, é reunida por diferentes autores. N este trabalho, buscamos didaticamente organizar os autores levantados a partir de três principais vertentes: a humanista, a social crítica e a da complexidade (Almeida, 2000). Essa classificação priorizou as características mais importantes, em nosso ponto de vista, dos trabal hos levantados, não significando, contudo, que autores encaixados no interior das diferentes vertentes não possam ter concordâncias de vários pontos de vistas entre si. Também não significa que não existam diversas heterogeneidades no interior de cada vertente, mas sim que existe uma certa ênfase dada por cada autor correspondente às características daquela vertente.

\section{A vertente humanista}

Uma primeira e pioneira vertente parte da filosofia do sujeito, em uma perspectiva humanista e pedagógica, para propor a busca de um diálogo ecumênico e reflexivo entre as várias áreas do conhecimento, centrando a transformação numa mudança de espírito dos próprios pesquisadores e do sistema de ensino (Japiassu, 1992; M artins de Sá, 1995).

Para esses autores, a superação do positivismo científico só seria possível através da articulação entre pesquisa e ensino, e ganha importância a figura do educador interdisciplinar, que não pode mais ser entendido como "transmissor de conhecimentos já feitos", mas como um constante provocador de um conhecimento humanista, cuja proposta utópica de ensino tem por compromisso a elaboração de uma teoria geral da cultura, capaz "de integrar todos os saberes em vista do fazer, dentro do conjunto da envergadura do espírito e do sentido da totalidade humana" (Japiassu, 1992).

Importantes por introduzirem o debate sobre a interdisciplinaridade e resgatarem a dimensão ética e humana na produção do conhecimento, os autores desta vertente, contudo, não aprofundam claramente quais devem ser as estratégias conceituais e metodológicas que visem operacional izar a integração das disciplinas para além de um espaço genérico de ensino humanista. 


\section{A vertente social crítica}

Uma segunda vertente realiza a crítica da primeira por seu caráter fetichista de uma pan-interdisciplinaridade, sem a realização da necessária reconstrução histórica, o que poderia fazer de algumas propostas de interdisciplinaridade uma "panacéia" para o combate a todos os males do campo científico. Os autores desta vertente centralizam sua análise na dimensão histórica e social da produção do conhecimento, ancorados numa crítica marxista que vê a ciência moderna subordinada à lógica da divisão social e técnico-científica do trabalho, no modo de produção capitalista (Coimbra, 1990; Frigotto, 1995; M inayo, 1994; Jantsch e Bianchetti, 1995; Severino, 1995).

Aqui, a produção de conhecimento é analisada dialeticamente como instrumento de poder. De um lado, servindo à lógica de estruturação, dominação e reprodução social, por meio de um discurso "neutro" e despolitizador que demarca os ter ritórios de especialistas técnico-científicos; de outro, como instrumento de transformação na produção de uma nova ordem, onde "o queé marginal, subterrâneo e reprimido possa aparecer com força e se afirmar" (Coimbra, 1990). Dessa forma, destaca-se uma perspectiva construtivista, tendo por eixo as re lações entre o sujeitos/pesquisadores e os objetos de estudo/sujeitos históricos, numa sinergia entre produção de conhecimento e transformação social. 0 debate sobre interdisciplinaridade precisaria assumir a materialidade histórica, sob pena de tornar-se uma discussão lógico-formal, discursiva (Frigotto, 1995). Nesse contexto, a construção e força das estratégias de integração disciplinar, bem como seus limites e possibilidades, seriam decorrentes da inserção social dos grupos de investigação, da produção de diagnósticos cientificamente fundamentados, da opção por um formato de pesquisa-ação e da reflexão conjunta entre pesquisadores e os sujeitos coletivos.

Esta vertente assume marcos referenciais que se sintonizam com a origem e as propostas da medicina social latino-americana e do campo da saúde coletiva. Suas discussões entre os autores levantados, contudo, não aprofundam as diferenças conceituais e operacionais entre as diversas estratégias de integração disci plinar.

\section{A vertente da complexidade e a noção deobjeto/problema complexo}

Por fim, uma terceira vertente possui como característica central uma crítica epistemológica à ciência contemporânea, a partir da incorporação da temática da complexidade e da perspectiva sistêmica, contribuindo para o aprofundamento teórico-metodológico em torno das diferentes estratégias de integração disciplinar. Suas origens se encontram na evolução da teoria de sistemas, inicialmente vinculada à cibernética e que se al astrou aos demais campos científicos e na discussão epistemológica com origem nas ciências sociais e humanas (M orin, 1996).

Um espaço particularmente profícuo dos trabal hos desta vertente encontra-se no campo das ciências ambientais, em particular com a evolução do conceito de ecossistema e com a mobilização social e científica em torno dos problemas ambientais modernos. Tais problemas decorrem de riscos ambientais globais sem precedentes do ponto de vista de sua complexidade e potenciais conseqüências, como as decorrentes das mudanças climáticas, dos efeitos da biotecnologia e dos desastres provocados por contaminações químicas crônicas ou acidentais. Neles, as incertezas são muitas e radicais, os valores e interesses são elevados, e se fazem necessárias tomadas de decisões rápidas, o que vem corroborando a crítica ao papel e legitimidade da ciência e dos cientistas na atualidade ( García, 1994; Funtowicz \& Ravetz, 1994 e 1997; Funtowicz e De M archi, 2001).

0 tema da complexidade também vem sendo debatido no campo da saúde coletiva por alguns autores, que por isso foram incorporados a esta vertente (Almeida Filho, 1997; Tarride, 1998; Samaja, 2000; Paim eAlmeida Filho, 2000). Em todos eles, é enfatizada a necessidade de a ciência resgatar sua capacidade de gerar sínteses diante de um mundo cada vez mais fragmentado e com graves desafios a serem enfrentados. Tal capacidade, relegada a segundo plano ao longo da história da ciência ocidental, é considerada um atributo essencial na construção de um novo modelo de ciência que supere as dicotomias simplificadoras e alienantes da ciência normal.

Pela sua relativa novidade e importância para os objetivos deste trabal ho, apresentaremos nesta vertente, ainda que resumidamente, 0 entendimento do que são sistemas ou objetos complexos. Tais conceitos possuem diferentes nuanças nos vários autores, sendo aqueles proveni- 
entes do campo ambiental mais pragmáticos em suas concepções e no papel das várias modalidades de conhecimento científico. Para Funtowicz e Ravetz (1994 e 1997) existem duas grandes classes de sistemas: os sistemas simples ou complicados, estudados pelas ciências naturais fisicalistas; e os sistemas complexos, estudados pelas ciências da vida como a ecologia e as ciências sociais e humanas. A principal diferença entre esses dois grupos de sistemas seria a impossibilidade do segundo ser compreendido por uma perspectiva única sem a perda de aspectos essenciais do sistema em relação aos problemas analisados.

Os sistemas complexos, por sua vez, possuiriam dois níveis ou ordens de complexidade: a) a ordinária, característica dos sistemas biológicos, na qual existiria uma ausência da autoconsciência e de propósitos mais completos, com um padrão de organização mais voltado à complementaridade de competências e de cooperação, como a predação, o parasitismo ea simbiose; b) a emergente ou reflexiva, característica dos si stemas sociais, técnicos ou mistos envolvendo os seres humanos. Ambas as complexidades ordinária ou reflexiva - dependeriam da diversidade para sua própria sustentabilidade, mas na complexidade ordinária esta diversidade seguiria padrões naturais de equilíbrio dinâmico contra as perturbações, através da interação de diversos elementos e subsistemas, em diferentes espaços e níveis de agregação em que se estruturam os ecossi stemas. Já a complexidade reflexiva oscilaria entre a hegemonia e a fragmentação, e não poderia ser explicada de forma mecanicista ou funcionalista. Como conseqüência da atuação dos seres humanos, estes sistemas possuem características como individualidade em conjunto com algum grau de intencionalidade, consciência, prospectiva, propósito, representações simbólicas e moralidade (Funtowicz e De M archi, 2001).

Garcia (1994), outro autor do campo ambiental, explica de outra forma porque um sistema complicado não é necessariamente complexo: Além da heterogeneidade, a característica de terminante de um sistema complexo é a interdefinibilidade e mútua dependência das funções que cumprem esses elementos dentro do sistema atual. Já Almeida Filho (1997), autor que discute a complexidade no âmbito da saúde coletiva, o objeto complexo pode ser compreendido como formado por múltiplas faces, ou seja, como "alvo de diversas miradas, fonte de múltiplos discursos, extravasando os recortes disci- plinares da ciência". Em outras palavras, o objeto complexo é "sintético, não linear, múltiplo, plural e emergente", justificando uma abordagem em que a organização convencional da ciência, em disciplinas autônomas e até estanques, é "superada por novas modalidades de práxis científica, instaurando formas alternativas da disciplinaridade".

Problemas ambientais e sanitários são bons exemplos de objetos complexos justamente porque envolvem simultaneamente o meio físicobiológico, a produção, a organização social, a economia ea cultura em sua interação com corpos humanos e ecossistemas, que podem com isso adquirir características de mais saúde ou vulnerabilidade frente aos riscos. A análise fragmentada de qualquer uma dessas dimensões, tal como realizada pela ciência normal ou mesmo pelos estudos multidisciplinares, acarretaria em graves problemas tanto analíticos quanto éticos, e incorreria em propostas limitadas de soluções.

\section{As diferentes estratégias de integração disciplinar: multi, inter etransdisciplinaridade}

N este artigo, optamos pelo uso do termo estratégias de integração disciplinar para reunir as possibilidades de produção de conhecimento multidisciplinar, interdisciplinar ou transdisciplinar, em oposição ao conhecimento monodisciplinar, significando o conjunto de propostas de integração entre as diversas disciplinas científicas na produção de conhecimento, em particular na análise de objetos complexos, bem como a integração entre a produção de conhecimentos e as estratégias de intervenção em torno de problemas particulares. Esta opção pelo termo estratégias de integração disciplinar é influenciada tanto pela carência de posições consensuais so bre os significados das várias estratégias de articulação disciplinar, como por nossa experiência no campo ambiental, em que a expressão inglesa integrated assessment vem sendo utilizada como alternativa às várias abordagens que visam superar os limites das abordagens científicas clássicas diante de problemas sócio-ambientais complexos, cuja busca de soluções passaria pela integração e síntese entre ciência, tecnologia, política e estilos de vida (Ravetz, 1999).

De forma geral, podemos assumir as estratégias de integração disciplinar como reunindo três grandes formas de articulação de discipli- 
nas na produção de conhecimento, tendo por referência o esquema apresentado por Almeida Filho (1997):

a) a multidisciplinaridade como o conjunto de disciplinas que se agrupam em torno de um dado tema desenvolvendo investigações e análises isoladas por diferentes especialistas, sem que se estabeleçam relações conceituais ou me todológicas entre elas. Corresponde à estratégia mais limitada, pois continuam a se reproduzir práticas fragmentadas da ciência normal, ainda que se avance na incorporação de múltiplas dimensões de um problema;

b) a interdisciplinaridade como a reunião de diferentes disciplinas articuladas em torno de uma mesma temática com diferentes níveis de integração, desde uma cooperação de comple mentaridade sem articulações axiomáticas ou preponderância de uma disciplina sobre as de mais (pluridisciplinaridade), passando pela preponderância de uma delas sobre as demais com ou sem uma axiomática comum (denominadas respectivamente como interdisciplinaridade estrutural ou auxiliar);

c) finalmente, a transdisciplinaridade corresponderia a uma radicalização da interdisciplinaridade, pela articulação de um amplo conjunto de disciplinas em torno de um campo teórico e operacional particular, sobre a base de uma axiomática comum e envolvendo um sistema de disciplinas articuladas em diferentes níveis, cuja coordenação se daria pelas finalidades e axiomática comuns. Esse tipo de integração possibilita o desenvolvimento de teorias e conceitos transdisciplinares, cuja aplicação é compartilhada por diferentes disciplinas e abordagens que atuam num campo teórico e operacional.

Esta classificação possui um caráter introdutório e didático, não sendo objetivo deste artigo discutir extensamente as diferenças entre os vários autores consultados sobre as formas de articulação disciplinar sugeridas. Em resumo, podemos afirmar que, embora haja um certo consenso crítico sobre características da multidisciplinaridade para superar os limites da ciência normal, observa-se uma grande heterogeneidade na utilização dos termos interdisciplinaridade e transdisciplinaridade, freqüentemente utilizados com significados muito semelhantes entre si.

Como observa M inayo (1994), é praticamente impossível conceituar consensualmente a interdisciplinaridade. Para a autora, haveria duas formas de interdisci plinaridade: uma implícita, interna, própria da racionalidade científica que, pelo avanço de conhecimentos acaba criando novas disciplinas; e outra constituída externamente por campos operativos que articulam ciência, técnica e política, sobretudo, por meio de intervenções sociais, como é o caso da saúde pública. Esta última visão se aproxima do conceito de transdisciplinaridade proposto tanto por Almeida Filho (1997) como por Funtowicz e Ravetz (1994).

Já Garcia (1994), um autor proveniente do campo ambiental, aprofunda de forma interessante e didática a discussão sobre aspectos metodológicos e operacionais da investigação interdisciplinar, definindo esta como a que investiga sistemas complexos como objetos de estudo ou problemas analisados. Estes seriam compreendidos a partir de uma totalidade, ou sistema, que conseguisse incorporar as principais dimensões explicativas, ainda que não controláveis, dos problemas/fenômenos em questão. Para Garcia, toda investigação interdisciplinar pressupõe marcos epistêmicos, conceituais e metodológicos compartidos entre os diferentes profissionais da equipe, possibilitando que problemas semel hantes possam ser definidos e estudados por diferentes enfoques interdisciplinares. Neste caso, a semelhança entre os objetos seria sempre relativa, dado que o ol har e os interesses associados a cada investigação interdisciplinar definiriam o próprio objeto de estudo.

Para Garcia (1994), a evolução dessetipo de estudo compreenderia um processo interativo e não linear de médio prazo, através de um movimento dialético entre duas fases: a de diferenciação, na qual estudos específicos tanto qualitativos quanto quantitativos são realizados por especialistas em etapas mais operacionais de diagnóstico de dimensões particulares do problema; e a de integração, em que seriam realizadas as integrações dos resultados obtidos no momento anterior, redefinindo a concepção do próprio sistema estudado, verificando e reformulando hipóteses de trabalho e gerando propostas alternativas de solução para os problemas em diferentes níveis. Num certo sentido, um projeto ou programa interdisciplinar nunca possui um fim preciso: sua finalização é mais o resultado de fatores como o término dos recursos e a entrega de certos resultados relevantes para as demandas que busca atender, através de relatórios com análises e recomendações, do que propriamente o esgotamento da intrincada trama de relações que demarcam os problemas complexos. 
Outra importante discussão refere-se à posição dos pesquisadores na qualidade de sujeitos da investigação interdisciplinar. Para Tambellini (1994), a prática interdisciplinar, como reconstrução do saber constituído, poderia se desenvolver a partir de duas possibilidades que coexistem: em trajetórias individualizadas por um sujeito de origem disciplinar que vai se apropriando de outros ol hares, ampliando seu olhar original; ou por intermédio de um processo coletivo em equipes multiprofissionais, em que vários sujeitos de distintas disciplinas debruçam-se em torno de um problema. Já Garcia (1994) considera ser sempre limitada a interdisciplinaridade solitária, realizada por um "sujeito interdisciplinar" ou um grupo de indivíduos com formações semelhantes, pois o entendimento de sistemas complexos também dependeria de uma multiplicidade de enfoques e estudos especializados, sendo indispensável a formação de equipes multiprofissionais com quadros competentes em suas áreas específicas de atuação. Complementando a posição de Garcia, M inayo (1994) considera ser um pré-requisito para o sucesso do empreendimento interdisciplinar a reunião de pesquisadores dispostos ao diálogo, competentes em suas áreas disciplinares, que possam articular conceitos comuns e realizar triangulações metodológicas, colaborando entre si na análise dos resultados. Almeida Filho (1997), por sua vez, coloca a necessidade de "operadores transdisci plinares da ciência" com o perfil anfíbio de trans-passarem as fronteiras e facilitarem o diálogo entre as distintas disciplinas científicas na construção de campos teóricos e operacionais de caráter transdisciplinar.

As estratégias de integração disciplinar, mais do que a ampliação do diálogo pela busca de uma maior organicidade entre os componentes internos da ciência, tornam mais evidente o necessário (re)encontro da ciência com a arte, a ética e a política. 0 diálogo, neste caso, não é só dos cientistas entre si, mas destes com a sociedade e com a própria consciência de cada um.

\section{Condições para a integração e a importância dos campos teóricos e operativos}

Conforme podemos concluir a partir desses autores, o sucesso de um empreendimento interdisciplinar depende de pesquisadores dispostos ao diálogo e com marcos referenciais construí- dos e compartilhados pela equipe de investigação. Este aspecto é fundamental para compreendermos algumas das dificuldades dos empreendimentos interdisciplinares: 0 simples juntar de pessoas com formações diferentes, mas sem os pré-requisitos colocados anteriormente, pode trazer mais problemas que soluções para a integração de conhecimentos e abordagens, resultando em estudos multidisciplinares fragmentados e elevados níveis de conflitos entre os profissionais da equipe.

Os sistemas universitários de formação tendem a produzir especialistas dogmatizados no interior de seus paradigmas e sem flexibilidade intelectual para dialogarem com outros profissionais de fora de sua área específica. A alternativa de pequenos grupos de pesquisa formados por poucos sujeitos interdisciplinares incorre nas limitações dos general ismos superficiais, dada sua incapacidade de estabelecerem sínteses que incorporem elementos e dimensões importantes dos problemas analisados com maior complexidade. Desta forma, a formação de equipes para investigações interdisciplinares de sucesso dependeria da conjugação de muitos elementos, como a aproximação de diversos profissionais em torno de problemas cujas próprias definições passariam por um processo de construção compartilhada. Por envolver engajamento e visões de mundo, a inexistência de afinidades políticas e pessoais entre os vários membros da equipe, combinada com intolerância e falta de disposição ao diálogo, pode inviabilizar o sucesso que se queira interdisciplinar.

A engenharia institucional que propicia tal aproximação é bastante complicada e depende de políticas institucionais de ciência e tecnologia que implementem medidas nesta direção, como facilitar a criação de grupos ou núcleos multiprofissionais e interdisciplinares dentro e entre as instituições de ensino e pesquisa. E as estruturas oficiais dos departamentos, centros e faculdades existentes nas instituições de pesquisa pouco contribuem nesta direção.

Os campos teóricos e operativos que envolvem simultaneamente diferentes áreas de conhecimento e práticas operacionais em torno de problemas complexos, como os campos ambiental (e dentre eles os campos da economia ecológica e da educação ambiental) e da saúde pública (e seus vários campos específicos ou subcampos, como a saúde do trabalhador, a saúde ambiental e a saúde mental), são espaços privilegiados para a formação de equipes multiprofissionais e estudos interdisciplinares, num pro- 
cesso iterativo de amadurecimento que pode levar à produção de conceitos e marcos teóricos transdisciplinares. Tais campos possuem um braço científico, representado pelas disciplinas eáreas mais específicas de conhecimento, e outro de caráter mais institucional e operativo, presente nas definições de políticas e nas práticas de instituições públicas ou mesmo privadas que se defrontam ebuscam enfrentar determinados problemas.

Estes campos congregam diferentes associações científicas e profissionais, eno Brasil a Abrasco possui o importante papel de articular profissionais da academia e dos serviços de saúde na discussão dos problemas de saúde pública do país. A trajetória da saúde coletiva brasileira, ao integrar espaços de reflexão teórica e práticas em saúde, explica o seu papel de destaque no país e o potencial futuro na produção de investigações interdisciplinares e marcos referenciais transdisciplinares. Dentre eles, podemos mencionar os possíveis desenvolvimentos decorrentes das discussões em torno do conceito de saúde - nos arcabouços mais abrangentes de uma teoria geral da saúde e das propostas operacionais da promoção da saúde -, bem como dos temas da eqüidade, exclusão e vulnerabilidade aplicadas ao campo da saúde coletiva.

\section{A integração disciplinar na emergência da saúde do trabalhador}

A emergência da saúde do trabal hador no Brasil nos anos 80 nos propicia um interessante espaço de reflexão sobre as possibilidades de integração disciplinar, numa área que envolve uma ampla mescla de conhecimentos e práticas em cenários sociais bastante complexos e conflitivos. Ela surge no interior do campo da saúde coletiva, sob influência dos pressupostos da medicina social latino-americana, da reforma sanitária italiana (modelo operário) no final dos anos 70, e do movimento pela reforma sanitária brasileira que culminou na institucionalização do SUS (M endes e Dias, 1991; Lacaz, 1997; M achado, 1997; M inayo-Gomez \& Thedim-Costa, 1997). Teve como apelo à integração o ideário ético-político dos técnicos/pesquisadores de solidariedade às lutas dos trabal hadores, cuja perspectiva assumiu a articulação entre assistência, pesquisa, sistematização das informações e intervenção sobre os fatores determinantes do risco, incluindo os ambientes de trabalho. Desta forma, buscou-se a reconstrução de um campo caracterizado até então pelo tecnicismo e pela fragmentação disciplinar einstitucional dominados pela medicina do trabal ho e pela engenharia de segurança do trabal ho (Porto, 1994).
Ao emergir como proposta acadêmica, política e institucional na saúde coletiva, a saúde do trabalhador promoveu algumas rupturas com as concepções hegemônicas envolvidas na temática saúde e trabalho, de caráter fortemente corporativo, eque estabeleciam um vínculo causal entre a doença e um agente específico (medicina do trabalho), ou entre a doença e um grupo de fatores de risco presentes no ambiente de trabalho (saúde ocupacional) (M endes \& Dias, 1991). O s conceitos e metodologias destas últimas trabalhariam sobre reduções sustentadas numa concepção monocausal ou multicausal não estruturada, em que o trabal ho é abordado através de sua especificidade etiológica simplificadora, ou seja, a doença clinicamente definida (Laurell \& Noriega, 1989).

Desta forma, a saúde do trabal hador foi gestada, desde o início, como um empreendimento de integração disciplinar, no qual as diversas disciplinas ou campos disciplinares não sejustaporiam, mas coexistiriam como complementares, no sentido de tentar reunir de maneira mais compreensiva aqueles fatores que permanecem à margem do âmbito da ação de cada uma delas isoladamente (Tambellini et al., 1986). Em outro artigo, esta mesma autora levanta a importância de se constituírem campos particulares na saúde pública que possibilitem o rompimento com uma certa dissociação entre os estudos epidemiológi cos, os de planificação e os de políticas, cada um operando sem considerar necessariamente os outros (Tambellini, 1994).

Ao contemplar o contorno social, econômico, político e cultural - definidor das relações particulares travadas nos espaços de trabal ho e do perfil de reprodução social dos diferentes grupos humanos -, e o referente às características dos processos de trabalho com potencial de repercussão na saúde ( M inayo-Gomez e Thedim-Costa, 1997), a saúde do trabalhador buscou articular estes dois planos de análise em suas manifestações concretas como objetos de estudo e estratégias de intervenção.

Tal perspectiva de integração entre investigação, formação e intervenção aparece na evolução e articulação orgânica entre os vários grupos de pesquisa surgidos nos anos 80-90, e na formação dos programas e centros de referência em saúde do trabalhador, estruturados em várias regiões do país no interior do SUS em instâncias de planejamento e execução nos seus níveis estadual e municipal. Pode-se dizer que as experiências de vigilância em saúde do trabalhador do SUS, a partir de grupos multi- 
profissionais e ações interinstitucionais, atuaram como importante elemento nas novas estratégias de integração disciplinar ( M achado, 1997; Lacaz, 1997; Porto, M achado e Freitas, 2000).

Neste processo, diferentes campos de conhecimento e profissionais foram se incorporando em torno dessas ações, com inserções diferenciadas nos espaços mais acadêmicos ou mais operacionais do SU S, ou ainda em assessorias no âmbito sindical. Freqüentemente tais inserções ocorreram - e ocorrem - de forma fluida entre os espaços acadêmicos e operativos, através da cooperação técnica e da formação dos profissionais em cursos de pós-graduação, particularmente nos centros urbanos mais desenvolvidos. Entre as várias áreas de conhecimento, graduações e especialidades envolvidas, destacam-se as ciências sociais e humanas ( como a psicologia, a assistência social e a sociologia), as ciências biomédicas (como a clínica e suas especialidades, a medicina do trabalho e a toxicologia), e áreas mais tecnológicas (como a higienee engenharia de segurança do trabal ho, a engenharia de produção e a ergonomia).

\section{Riquezas, riscos e desafios da interdisciplinaridade e da "indisciplinaridade" na saúde do trabalhador}

U ma questão a ser levantada aqui é de que forma podemos analisar a inserção acadêmica da saúde do trabal hador no interior do campo mais abrangente da saúde coletiva. De acordo com Almeida Filho (1997) e Campos (2000), a saúde coletiva pode ser considerada um campo por articular dimensões teóricas e operacionais em torno de problemas de saúde das populações, tendo objetivos e axiomáticas gerais comuns resultantes da trajetória da medicina social latino-americana e da reforma sanitária brasileira. A saúde do trabalhador caminha nessa direção, por conjugar espaços acadêmicos e operacionais em sua evolução. Entretanto, consideramos que a saúde do trabalhador chegou a se configurar de forma mais orgânica como espaço institucional e operativo do SU S, apesar de todas as suas dificuldades, do que numa área acadêmica claramente definida em termos de seu arcabouço conceitual e metodológico no âmbito da saúde coletiva. Existem vários motivos que explicam um certo pluralismo acadêmico e que propiciam tanto as riquezas das múltiplas abordagens quanto uma certa "indisciplinaridade" na articulação de tão vasto arcabouço teórico-metodológico.

Além da forte intersetorialidade, um componente marcante da área é a grande gama de disciplinas e corporações profissionais envolvidas, talvez a mais abrangente dentre as várias áreas de atuação da saúde coletiva. Diferentes profissionais oriundos das ciências médicas, tecnológicas, sociais e humanas estão envolvidos quando integramos o ciclo dos riscos presentes nos processos saúde-doença dos trabaIhadores: desde seus condicionantes sociais, econômicos e culturas mais gerais, até as características tecnológicas e organizacionais dos processos de trabal ho, seus efeitos ambientais e clínicos, formas de tratamento e recuperação. Essa abrangência, dialética e paradoxal, ao mesmo tempo em que aumenta as dificuldades de integração disciplinar, propicia espaços ímpares de integração entre os vários profissionais em torno dos mesmos problemas, como no desenvolvimento de ações de vigilância em saúde do trabalhador. Tamanha multiplicidade, articulada com intervenções operacionais em situações freqüentemente emergenciais, como acidentes fatais e doenças graves, mesclada ainda com doses de militância, voluntarismo e rebeldia que caracterizam a área, ajudam-nos a compreender as dificuldades organizacionais dos pesquisadores e profissionais em saúde do trabalhador.

Certamente existem vários aspectos positivos na forte imbricação existente entre investigação e inter venção nessa área. Um profissional de saúde do trabalhador parece incorrer menos no risco de reproduzir o dito oriental, tão válido para diversos campos e profissionais do mundo acadêmico, e que diz ser um sábio que não aplica seus conhecimentos semelhante a um burro carregando uma pilha de livros em seu lombo.

Por outro lado, a busca por se unir produção de conhecimento e transformação social pode incorrer numa valorização e aceitação tácita de qualquer conhecimento técnico-científico, desde que subordinado aos objetivos maiores de transformação social explicitados pelas equipes e projetos de investigação e intervenção. Tal tendência pode levar a dois problemas: a) a fragilidade dos critérios de qualidade para a incorporação de profissionais e para o desenvolvimento metodológico das investigações e análise dos resultados; b) o não-aprofundamento dos conflitos entre corpos de profissionais com paradigmas tão distintos coexistindo num diálogo não reflexivo, onde as mãos de uma equipe dita “in- 
terdisciplinar" freqüentemente tapam olhos e ouvidos aos ruídos e problemas de comunicação e relacionamento.

Esses problemas podem forjar trabalhos que se aproximam mais de uma multidisciplinaridade restrita, como somatório de abordagens fragmentadas de vários especialistas, ou ainda uma interdisci plinaridade restrita, realizada por um núcleo central de pesquisadores mais "interdisciplinares" que se apropriam de resultados produzidos por especialistas isolados. Freqüentemente discursos de conotação ideológica, muito presentes na área, encobrem as contradiç̃̃es e os conflitos conceituais e metodológicos entre os vários paradigmas presentes nas investigações, sem aprofundá-los em sua natureza epistemológica. Se tal estratégia viabiliza a convivência entre distintos profissionais e paradigmas, como médicos, engenheiros, toxicologistas e cientistas sociais, por sua vez também limita as possibilidades de reflexão, integração e renovação da prática científica.

Pessoalmente acredito que o risco do outro lado da moeda seja ainda mais imobilizador. Os estudos isolados, não-interdisciplinares, são bem menos problemáticos de serem realizados, pois possuem uma linguagem mais clara, com conceitos, métodos e critérios de qualidade meIhor estabelecidos por comunidades mais homogêneas de pesquisadores. M ais fácil ainda de se real izar são os projetos distantes e descontextualizados do complexo tecido político e institucional em que se dão os problemas de saúde pública e suas intervenções. N esses projetos, 0 aparente "distanciamento" e "neutralidade" dos pesquisadores pode parecer a alguns uma importante estratégia de objetivar as análises, re duzindo ainda o desgaste dos pesquisadores com as idiossincrasias de pessoas e instituições do mundo real. M as tais investigações tendem a se alienar das demandas e dinâmicas que estão no coração dos problemas analisados, e por isso ferem um princípio ético e político central da área de saúde do trabalhador.

Outro elemento complicador para uma maior organicidade acadêmica desta área está associado à falta de definição de uma política nacional de saúde do trabalhador no país. Todo novo campo de conhecimentos e práticas responde aos desafios e demandas de um quadro histórico mais amplo. Esse foi o caso, por exemplo, da ergonomia na França pós-guerra, estimulado por um ministério do trabalho nas mãos do Partido Comunista que priorizou a melhoria das condições do operariado francês (Porto, 1994).
Da mesma forma, a saúde do trabalhador possui uma natureza político-ideológica que foi fortemente abalada com a história recente pósmuro de Berlim e os avanços do neoliberal ismo e da globalização sobre os rumos da América Latina e do Brasil. Tais processos vêm minando a capacidade de organização e reivindicação dos trabal hadores e sindicatos justamente no período de redemocratização da sociedade brasileira no qual se esperavam grandes conquistas sociais. As diferentes composições políticas do governo federal nesse período impediram, na prática, a formulação de políticas sociais integradas mais globais em torno da proteção aos trabal hadores, sendo regra a fragmentação entre as ações preventivas, assistenciais e reparadoras, inclusive as previdenciárias. Um indicador desta limitação é a absoluta hegemonia de forças políticas conservadoras a frente das pastas do trabalho e da previdência social ao longo dos anos 90 , nas quais a força das corporações da medicina do trabal ho e da engenharia de segurança é preponderante. $0 \mathrm{~s}$ conflitos intersetoriais decorrentes das ações do SUS com os ministérios do Trabalho e da Previdência Social, em especial no tocante às ações de vigilância em ambientes de trabalho, resultam da indefinição de políticas integradas. Tal indefinição expressa o atual nível de conflito capital-trabal ho no país, num quadro político ainda bastante conservador e cujas disputas corporativas freqüentemente dificultam maiores avanços institucionais.

\section{Tendências e perspectivas atuais da área}

Não obstante todas as limitações políticas dos governos federais ao longo da década de 1990, a área de saúde do trabalhador continuou a crescer dentro do SUS nesse período, impulsionada pel os avanços democráticos localizados no âmbito regional e num certo voluntarismo característico da área. Tal crescimento pode ser observado pela expressiva participação, no período, de trabal hos ap resentados nos congressos brasilei ros de saúde coletiva, epidemiologia ou ciências sociais em saúde (Lacaz, 1996). Tais trabalhos são freqüente e simultaneamente vinculados tanto a atividades acadêmicas dos centros de pós-graduação, quanto de ações operacionais do SUS, sendo marcados por uma multiplicidade de referenciais teóricos e metodológicos em torno de diferentes problemas concretos. 0 forte caráter simbiótico entre aspectos 
político-institucionais e práticas de intervenção e mobilização social constituem-se na maior riqueza destes trabalhos, ao mesmo tempo em que limitam um maior rigor metodológico dos mesmos.

Com a evolução da temática ambiental no campo da saúde coletiva principalmente após a Rio 92, em consonância com as discussões teóricas sobre promoção da saúde com as demandas decorrentes da implementação da vigilância ambiental no SUS através do VIGISUS, observa-se uma maior aproximação de vários profissionais oriundos da área de saúde do trabaIhador na discussão ambiental. Por sua vez, autores como Tambellini e Câmara (1998) sugerem a constituição de um campo ou núcleo de investigações sobre a relação mais abrangente entre saúde, trabalho e ambiente ou produção, ambiente e saúde, que busca simultaneamente integrar e superar as áreas de saúde do trabalhador e saúde ambiental no atual momento histórico e institucional. A saúde ambiental desenvolveu-se na saúde pública fortemente impulsionada tanto pelo controle de fatores biológicos (vetores) como pelo desenvolvimento da engenharia sanitária e ambiental em torno de tecnologias de intervenção sobre fatores de risco ambiental, em especial problemas de saneamento básico, possuindo até o momento um papel relativamente restrito na conformação teórica e política da saúde coletiva.

Atualmente, podemos observar algumas tendências interessantes no país sobre a evolução da investigação em saúde do trabalhador ou, em sua perspectiva mais abrangente, em saúde, trabalho e ambiente, tais como:

a) a formação de mestres e doutores na área, possibilitando a expansão de vários cursos de pós-graduação, em nível de especialização ou mestrado/doutorado, em instituições com subáreas de concentração e linhas de pesquisa em saúde, trabalho e ambiente, com uma importante presença de profissionais e temas vinculados ao SUS;

b) vários grupos de pesquisa oficialmente registrados no diretório de grupos de pesquisa do CNPq com equipes multiprofissionais. Como é possível ver no portal do CNPq (www.cnpq.br), atualmente existem cerca de 50 grupos de pesquisa diretamente envolvidos na temática saúde do trabalhador, e 17 na temática saúde, trabalho e ambiente na versão 4.0 do Diretório de Grupos de Pesquisa.

Vários grupos e trabalhos apontados anteriormente vêm buscando integrar dimensões qualitativas e quantitativas em torno de problemas de saúde, trabalho e ambiente em grupos populacionais específicos, com uma pluralidade de enfoques conceituais e metodológicos de acordo com as características de formação dos grupos de pesquisa e dos objetos de estudo. A presença de temáticas transversais contribui para o desenvolvimento de estratégias inter/ transdisciplinares e constituem-se, desta forma, em experimentos acadêmicos e sociais que podem contribuir na construção e aprimoramento de novas práticas científicas e institucionais de integração disciplinar.

A atual crise decorrente das transformações no mundo do trabal ho ena sociedade como um todo traz novos desafios para este campo de investigação na realidade brasileira. 0 terreno sociopolítico e econômico dos anos 80, época do fortal ecimento da área de saúde do trabalhador na saúde coletiva brasileira, em consonância com o processo de redemocratização da sociedade e da reforma sanitária, foi seguido nos anos 90 pela expansão do desemprego e do trabalho informal (Druck e Franco, 1998), acarretando um recrudescimento do movimento sindical e dificultando a força da aliança entre os movimentos sanitarista e sindical, o que vem exigindo novos enfoques tanto para as práticas do SUS como para a investigação, por exemplo por meio de estudos sobre o trabalho informal e a violência nos centros urbanos ( $\mathrm{M}$ inayo-Gomez e Thedim-Costa, 1999).

Outro desafio importante, de caráter tanto conceitual quanto operacional, provém das discussões sobre a questão ambiental e a promoção da saúde que, em sua vertente crítica, pode nos ajudar a repensar problemas de saúde de forma mais integrada. Tais discussões deslocam o referencial biomédico centrado na doença, para a compreensão e promoção de indivíduos, comunidades e políticas públicas saudáveis. A noção de saúde de ecossistemas (Waltner-Toews, 2001) e a abordagem eco-social em saúde (Levins e Lopez, 1999; Possas, 2001) são interessantes contribuições para a construção de novas estratégias disciplinares e referenciais transdisciplinares para a saúde coletiva.

Desafios como estes somente poderão ser enfrentados pelos vários grupos de pesquisa por intermédio de criatividade e um claro compromisso ético, integrando pesquisadores com diferentes especialidades que produzam visões compartilhadas e abrangentes sobre os problemas analisados, ao mesmo tempo em que geram estratégias operacionais de intervenção. Trata-se 
de construir não somente estratégias de integração entre as disciplinas, mas de integrar a produção de conhecimento com a sociedade, suas demandas e forças transformadoras. As estraté gias de integração disciplinar envolvem simultaneamente dimensões éticas, epistemológicas, políticas e institucionais que precisam ser mescladas numa nova prática científica, contribuindo para a construção de um país e um planeta mais justo, sustentável, democrático e plural.

\section{Referências bibliográficas}

Almeida GES 2000. Pra que somar se a gente pode dividir? Estratégias de integração disciplinares: saúde, trabalho e ambiente. Dissertação de mestrado. Escola Nacional de Saúde Pública. ENSP/Fiocruz, Rio de Janeiro, 178pp.

Almeida Filho N 1997. Transdisciplinaridade e saúde cole tiva. Rio de Janeiro. Ciência \& Saúde Coletiva 2 (1/2).

Campos GW 2000. Saúde pública e saúde coletiva: campo e núcleo de saberes e práticas. Ciência $\&$ Saúde Coletiva 5(2):21-230.

Coimbra CM B 1990. A divisão social do trabalho e os especialismos técnico-científicos. Revista do Departamento de Psicologia da UFF, ano II(2).

Collins HM 1983. The sociology of scientific knowledge: studies of contemporary science. Annual Reviews of Sociology v. 9:265-85.

Druck G \& Franco T 1998. A degradação do trabalho e os riscos industriais no contexto da globalização, reestruturação produtiva e das políticas neoliberais, pp. 1532. In Franco, T. (org.). Trabalho, riscos industriais e meio ambiente: rumo ao desenvolvimento sustentável?

Frigotto G 1995. A interdisciplinaridade como ncessidade e como problema nas ciências sociais. In Jantsch AP \& Bianchetti L. Interdisciplinaridade: para além da filosofia do sujeito. Vozes, Petrópolis.

Funtowicz S \& Ravetz J 1994. "Emerging complex systems". Futures 26:6.

Funtowicz S \& Ravetz J 1997. Ciência pós-normal e comunidades ampliadas de pares face aos desafios ambientais. História, Ciências, Saúde, vol. IV, jul.-out.

Funtowicz S\& De M archi B 2001. Ciencia posnormal, complejidad reflexiva y sustentabilidad, pp. 54-84. In Leff E. (ed.). La complejidad ambiental. Siglo XXI, M éxico.

Garcia R 1994. Interdisciplinaridad y sistemas complejos. In LEFF, E. et al. Ciencias Sociales y Formación Ambiental. Gedisa, Barcelona.
Jantsch AP \& Bianchetti L 1995. Universidade e Interdisciplinaridade [b]. In Jantsch AP \& Bianchetti L. (orgs.). Interdisciplinaridade: Para além da filosofia do sujeito. Vozes, Petrópolis.

Japiassu H 1992. A atitude interdisciplinar no sistema de ensino. Revista Tempo Brasileiro 108:83-94.

Kuhn T 1987. A estrutura das revoluções científicas. Perspectiva, São Paulo.

Lacaz FA 1996. Saúde do trabalhador: um estudo sobre as formações discursivas da academia, dos serviços e do movimento sindical. Tese de doutorado. Faculdade de Ciências M édicas da Unicamp, 435pp.

Lacaz FA 1997. Saúde dos trabalhadores: cenários e desafios. Cadernos de Saúde Pública, 13(2):7-19.

Latour B 1994. Jamais fomos modernos. Ed. 34, Rio de Janeiro.

Laurell AC \& Noriega M 1989. Processo de produção e saúde: trabalho e desgaste operário. Hucitec, São Paulo.

Levins RE \& Lopez C 1999. Toward an ecosocial view of health. International Journal of H ealth Services 29(2): 261-293.

M achado H 1997. Processo de vigilância em saúde do trabalhador. Cadernos de Saúde Pública, 13(2):33-45.

M artins de Sá JL 1995. Apresentação [a]. In M artins de Sá, J L (org.). Serviço social e interdisciplinaridade: dos fundamentos filosóficos à prática interdisciplinar no ensino, pesquisa e extensão, 2ª ed. Cortez, São Paulo.

M aturana H \& Varela F 1991. El árbol del conocimiento. Editorial Universitária, Santiago.

Mendes R \& Dias EC 1991. Da medicina do trabalho à saúde do trabalhador. Revista de Saúde Pública 25(5): 341-349.

M inayo M S 1994. Interdisciplinaridade: funcionalidade ou utopia? Revista Saúde e Sociedade 3(2):42-64.

Minayo-Gomez C \& Thedim-Costa SM da F 1997. A cons- 
trução do campo da saúde do trabalhador: percurso e dilemas. Cadernos de Saúde Pública 13(2):21-32.

M inayo-Gomez C \& Thedim-Costa SM F 1999. Precarização do trabalho e desproteção social: desafios para a saúde coletiva. Ciência \& Saúde Coletiva 4(2):263286.

Morin E 1996. O desafio da complexidade. In Ciência com consciência. Bertrand Brasil, Rio de Janeiro.

Paim JS \& Almeida Filho N 2000. A crise da saúde pública e a utopia da saúde coletiva. Casa da Qualidade Editora, Salvador.

Porto M F de S 1994. Trabalho industrial, saúde e ecologia. Tese de doutorado. COPPE/UFRJ. Rio de Janeiro, 428pp.

Porto M F de S \& Freitas CM 1997. Análise de riscos tecnológicos ambientais: perspectivas para o campo da saúde do trabalhador. Cadernos de Saúde Pública 13(2): 59-72.

Porto M F des; M achado JM H \& Freitas CM 2000. Promoção da saúde e intersetorialidade: a experiência da vigilância em saúde do trabalhador na construção de redes. In Anais do VI Congresso Brasileiro de Saúde Coletiva. Salvador: Abrasco e ISC/U FBA, Salvador.

Possas CA 2001. Social ecosystem health: confronting the complexity and emergence of infectious diseases. Cadernos de Saúde Pública 17(1):31-41.
Ravetz J 1999. Developig the principles of good practice in integrated environmental assessment. International Journal of Environmental and Pollution 11(3):243-265.

SamajaJ 2000. A reprodução social ea saúde: elementos metodológicos sobrea questão das relações entre saúde e condições de vida. Casa da Qualidade Editora, Salvador.

Severino AJ 1995. 0 uno e o múltiplo: o sentido antropológico do interdisciplinar [b]. In Jantsch AP \& Bianchetti L 1995. Interdisciplinaridade: para além da filosofia do sujeito. Vozes, Petrópolis.

Tambellini AT et al. 1986. Política nacional de saúde dos trabalhadores: análises e perspectivas. I Conferência Nacional de Saúde dos Trabalhadores. Abrasco/Fiocruz, Rio de Janeiro.

Tambellini AT 1994. Interdisciplinaridad y formación de recursos humanos para el area de salud en el area de salud del trabajador y ecología humana. In Rodriguez MI (coord.). Lo biológico y lo social. OPS/OMS, Washington D.C.

Tambellini AT \& CâmaraV de M 1998. A temática saúdee ambiente no processo de desenvolvimento do campo da saúde coletiva: aspectos históricos, conceituais e metodológicos. Ciência \& Saúde Coletiva, 3(2):47-59.

Tarride IM 1998. Saúde pública: uma complexidade anunciada. za ed. Fiocruz, Rio de Janeiro.

Waltner-Toews D 2001. An ecosystem approach to health and its applications to tropical and emerging diseases. Cadernos de Saúde Pública 7(Suplem.):7-36.

Artigo apresentado em 10/10/2001 Versão final apresentada em 8/3/2002 Aprovado em 25/3/2002 